\title{
Predictors of an academic career among fellowship-trained open vascular and endovascular neurosurgeons
}

\author{
*Adham M. Khalafallah, MD, Adrian E. Jimenez, BS, Justin M. Caplan, MD, \\ Cameron G. McDougall, MD, Judy Huang, MD, Debraj Mukherjee, MD, MPH, and \\ Rafael J. Tamargo, MD
}

Department of Neurosurgery, Johns Hopkins University School of Medicine, Baltimore, Maryland

\begin{abstract}
OBJECTIVE Although previous studies have explored factors that predict an academic career among neurosurgery residents in general, such predictors have yet to be determined within specific neurosurgical subspecialties. The authors report on predictors they identified as correlating with academic placement among fellowship-trained vascular neurosurgeons.

METHODS A database was created that included all physicians who graduated from ACGME (Accreditation Council for Graduate Medical Education)-accredited neurosurgery residency programs between 1960 and 2018 using publicly available online data. Neurosurgeons who completed either open vascular or endovascular fellowships were identified. Subsequent employment of vascular or endovascular neurosurgeons in academic centers was determined. A position was considered academic if the hospital of employment was affiliated with a neurosurgery residency program; all other positions were considered non-academic. Bivariate analyses were conducted using Fisher's exact test or the MannWhitney U-test, and multivariate analysis was performed using a logistic regression model.
\end{abstract}

RESULTS A total of 83 open vascular neurosurgeons and 115 endovascular neurosurgeons were identified. In both cohorts, the majority of neurosurgeons were employed in academic positions after training. In bivariate analysis, only 2 factors were significantly associated with a career in academic neurosurgery for open vascular neurosurgeons: 1) an $h$-index of $\geq 2$ during residency (OR 3.71, $p=0.016)$, and 2) attending a top 10 residency program based on U.S. News and World Report rankings (OR 4.35, $p=0.030$ ). In bivariate analysis, among endovascular neurosurgeons, having an $h$-index of $\geq 2$ during residency (OR 4.35, $p=0.0085$ ) and attending a residency program affiliated with a top 10 U.S. News and World Report medical school (OR 2.97, $p=0.029$ ) were significantly associated with an academic career. In multivariate analysis, for both open vascular and endovascular neurosurgeons, an $h$-index of $\geq 2$ during residency was independently predictive of an academic career. Attending a residency program affiliated with a top 10 U.S. News and World Report medical school independently predicted an academic career among endovascular neurosurgeons only.

CONCLUSIONS The authors report that an $h$-index of $\geq 2$ during residency predicts pursuit of an academic career among vascular and endovascular neurosurgeons. Additionally, attendance of a residency program affiliated with a top research medical school independently predicts an academic career trajectory among endovascular neurosurgeons. This result may be useful to identify and mentor residents interested in academic vascular neurosurgery.

https://thejns.org/doi/abs/10.3171/2020.2.JNS2033

KEYWORDS academic career; residency; vascular neurosurgery; vascular disorders

$\mathrm{T}$ HE identification and mentoring of neurosurgery residents likely to pursue an academic career is an important goal of most neurosurgery training programs. Although several studies have explored predictors of an academic career in neurosurgery in general, few have addressed the likelihood of pursing an academic career within the neurosurgical subspecialties. ${ }^{1-6}$ In orthopedics, Park and colleagues identified 3 factors associated with an increased likelihood of spine surgery applicants pursuing an academic career, namely, completion of a research fellowship, graduation from a top 20 medical school, and a stated desire in the personal statement to become an aca-

ABBREVIATIONS ACGME = Accreditation Council for Graduate Medical Education. SUBMITTED January 4, 2020. ACCEPTED February 11, 2020.

INCLUDE WHEN CITING Published online April 17, 2020; DOI: 10.3171/2020.2.JNS2033.

${ }^{*}$ A.M.K. and A.E.J. contributed equally to this work. 
demic surgeon. ${ }^{7}$ In pediatric neurosurgery, predictors of academic productivity as measured by the $h$-index have been analyzed after completion of fellowship. ${ }^{8,9}$ In neurosurgery, however, factors that predict academic placement after fellowship have not been explored.

Subspecialization in vascular neurosurgery typically requires dedicated training during residency and, increasingly, a postgraduate or infolded fellowship in either open vascular or endovascular training. Furthermore, academic productivity is a hallmark of vascular neurosurgery in general and a marker for residents interested in vascular neurosurgery in particular. A recent study of publications from residents in Accreditation Council for Graduate Medical Education (ACGME)-accredited neurosurgery training programs showed that the most common subspecialty among all resident publications was vascular neurosurgery (24.9\%), followed by spine (16.9\%) and oncology $(16.1 \%)$, with an average $h$-index per resident in all subspecialties of 2.5. ${ }^{10}$

In this study, predictors of an academic career trajectory among fellowship-trained vascular neurosurgeons were evaluated. Given the recent trend within vascular neurosurgery to pursue fellowship training in either open vascular or endovascular techniques, characteristics of graduates in both subdisciplines were identified and contrasted. We report on the predictors identified as being correlated with academic placement within vascular neurosurgery.

\section{Methods \\ Data Set Creation}

A database of all physicians who graduated from ACGME-accredited neurosurgery residency programs between 1960 and 2018 was created. Alumni/alumnae information was primarily obtained from neurosurgery residency program websites, and these data were verified and supplemented using information in Google and from LinkedIn. Publication and citation information for each time period (i.e., before, during, and after residency) for each neurosurgeon was obtained using Web of Science and analyzed independently.

\section{Variables Analyzed}

For each fellowship-trained neurosurgeon, the following information was collected: sex, medical school graduation year, residency program name and graduation year, length of residency training, months of protected research time during training, and $h$-indices before residency (i.e., at the time prior to starting residency), during residency (i.e., at the time of graduation from residency), and after residency. The number of clinical fellowships completed, fellowship types, and fellowship locations were recorded for all graduates. Neurosurgeons who completed both an open vascular and an endovascular fellowship were counted in both cohorts. Current employment location of each graduate was recorded, and it was determined whether it was an academic neurosurgery center. A position was considered academic if the hospital of employment was affiliated with a neurosurgery residency program; all other positions were considered non-academic.

Medical schools and neurosurgical training programs were categorized as follows. A "top" medical school was defined as an institution listed within the top 10 rankings of the U.S. News and World Report list for "Best Medical Schools: Research" at least once within the years 19932019. A top residency program was defined as an institution listed at least once within the top 10 rankings of the U.S. News and World Report list for "Best Hospitals for Neurology and Neurosurgery" between the years 2007 and 2019. Finally, whether graduates completed their neurosurgical training at a residency program affiliated with an aforementioned top research medical school was recorded. A comprehensive list of the top educational institutions for the purposes of this study is shown in Table 1.

\section{Statistical Analysis}

Data were collected using Microsoft Excel (version 2016, Microsoft Corp.). Statistical analyses were conducted using $\mathrm{R}$ statistical software (version 3.3.2, r-project. org). The Shapiro-Wilk test was used to test for normality. Categorical variables were analyzed using Fisher's exact test, and continuous variables were analyzed using the Mann-Whitney U-test. For the Mann-Whitney Utest, difference in location was defined as the median of the difference between a sample from the open vascular neurosurgeon cohort and the endovascular neurosurgeon cohort. In addition to $\mathrm{p}$ values, odds ratios and $95 \%$ confidence intervals were calculated for bivariate analysis of independent and dependent variables. Multivariate analysis was conducted using logistic regression, with variables having a significance level of $\mathrm{p}<0.05$ in bivariate analysis serving as covariates in the model. Covariates in the openvascular cohort analysis were automatically included as covariates in the endovascular cohort analysis and vice versa. Attainment of a $\mathrm{PhD}$ degree was also included as a covariate in our logistic regression models because of prior studies that have demonstrated the degree's ability to independently predict academic career choice. ${ }^{3}$ Values of $p<0.05$ were considered statistically significant, and $p$ values are reported as two-sided.

\section{Results \\ Predictors of Academic Career Choice in Vascular Neurosurgery}

Among open vascular neurosurgeons, by bivariate analysis, only 2 factors were significantly associated with a career in academic neurosurgery: 1) an $h$-index of $\geq 2$ during residency (OR 3.71, 95\% CI 1.15-12.94; $\mathrm{p}=0.016$ ) compared with an $h$-index of $0-1$; and 2) attending a top 10 residency program by U.S. News and World Report rankings (OR 4.35, 95\% CI 1.09-25.56; $\mathrm{p}=0.030$ ). Among endovascular neurosurgeons, by bivariate analysis, significant predictors of academic career choice included 1) having an $h$-index of $\geq 2$ during residency (OR $4.35,95 \%$ CI 1.32-16.90; $\mathrm{p}=0.0085$ ) compared with having an $h$-index of $0-1$; and 2) attending a residency program affiliated with a top U.S. News and World Report research medical school (OR 2.97, 95\% CI 1.08-9.13; p = 0.029). Table 2 shows the bivariate analysis used to determine predictors of academic career placement among both open vascular neurosurgeons and endovascular neurosurgeons. Notably, 
TABLE 1. List of top medical schools and neurosurgery residency programs (in alphabetical order)

\begin{tabular}{|c|c|c|}
\hline $\begin{array}{c}\text { Top } 10 \text { U.S. News Research Medical } \\
\text { Schools (1993-2019) }\end{array}$ & $\begin{array}{l}\text { Top } 10 \text { U.S. News Residency } \\
\text { Programs (2007-2019) }\end{array}$ & $\begin{array}{l}\text { Residency Programs Affiliated With a Top } 10 \text { U.S } \\
\text { News Research Medical School (1993-2019) }\end{array}$ \\
\hline Columbia University & Barnes-Jewish Hospital & Brigham \& Women's Hospital \\
\hline Cornell University & Cleveland Clinic & Columbia University \\
\hline Duke University & $\begin{array}{l}\text { Hospitals of the University of Pennsylvania-Penn } \\
\text { Presbyterian }\end{array}$ & Cornell University \\
\hline Harvard University & Johns Hopkins Hospital & Duke University \\
\hline Johns Hopkins University & Massachusetts General Hospital & Johns Hopkins University \\
\hline Mayo Clinic School of Medicine & Mayo Clinic (Rochester, MN) & Massachusetts General Hospital \\
\hline New York University & Methodist Hospital (Houston, TX) & Methodist Hospital (Houston, TX) \\
\hline Stanford University & NewYork-Presbyterian Hospital-Columbia \& Cornell & New York University \\
\hline University of California, Los Angeles & New York University Langone Hospitals & Stanford University \\
\hline University of California, San Francisco & Northwestern Memorial Hospital & University of California, Los Angeles \\
\hline University of Chicago & Rush University Medical Center & University of California, San Francisco \\
\hline University of Michigan & St. Joseph's Hospital-Barrow (Phoenix, AZ) & University of Michigan \\
\hline University of Pennsylvania & Stanford Healthcare-Stanford Hospital & University of Pennsylvania \\
\hline University of Washington & University of California, Los Angeles Medical Center & University of Washington \\
\hline Washington University in St. Louis & University of California, San Francisco Medical Center & Washington University in St. Louis \\
\hline \multirow[t]{2}{*}{ Yale University } & University of Michigan Hospitals-Michigan Medicine & Yale University \\
\hline & University of Pittsburgh Medical Center & \\
\hline
\end{tabular}

completing a fellowship at one of the top 2 institutions that graduated the most fellows was not significantly associated with academic career choice for either open vascular or endovascular neurosurgery.

By multivariate logistic regression analysis, in both open vascular and endovascular neurosurgeons, attaining an $h$-index of $\geq 2$ during residency was independently predictive of an academic career. For endovascular neurosurgeons, attendance of a residency program affiliated with a top research medical school also independently predicted an academic career. Interestingly, in this cohort a combined MD-PhD degree was not correlated with an academic career. These results are summarized in Table 3.

\section{Differences Between Fellowship-Trained Open Vascular and Endovascular Neurosurgeons}

The only significant difference between the two groups was the number of fellowships completed, with open vascular neurosurgeons having completed significantly more clinical fellowships than endovascular neurosurgeons $(\mathrm{p}=$ 0.0014 , difference in location $7.23 \times 10^{-6}$ ). Whereas $39.8 \%$ $(33 / 83)$ of open vascular neurosurgeons completed more than 1 fellowship, $19.1 \%$ (22/115) of endovascular neurosurgeons did the same. Table 4 shows the characteristics for both open vascular and endovascular neurosurgeons. Importantly, a total of 19 neurosurgeons completed both open vascular and endovascular fellowships (by completing 2 or more fellowships). Table 5 displays the characteristics of these dual-trained vascular neurosurgeons.

\section{Vascular Neurosurgery Fellowship Programs}

For both open vascular and endovascular fellowship programs, the institutions that have produced the most fellowship-trained graduates were identified. The top 6 institutions in terms of open vascular neurosurgery fellows are Barrow Neurological Institute (Phoenix; $n=11$ ), Thomas Jefferson University $(n=6)$, Emory University $(n=5)$, University of Miami $(n=4)$, University of South Florida $(n=4)$, and University of Washington $(n=4)$. The top 6 institutions in terms of endovascular neurosurgery fellows are University at Buffalo $(\mathrm{n}=11)$, Barrow Neurological Institute (Phoenix; $\mathrm{n}=10$ ), University of Florida ( =9), Thomas Jefferson University $(n=8)$, Albany Medical College $(n=5)$, and Harvard University $(n=5)$. The results are summarized in Table 6.

\section{Discussion}

Prior Research

Several studies have investigated factors that may lead students and trainees to pursue careers in academic neurosurgery. Describing the experience at the Johns Hopkins University School of Medicine, Brem and Amundson noted that departmental efforts to provide extensive clinical, research, and mentorship opportunities between students and faculty within a supportive environment have led to large numbers of medical students choosing to pursue careers in academic neurosurgery. ${ }^{11}$ A study by Karsy et al. investigated resident attitudes toward research and scholarship, noting that scholarly output affects the likelihood of pursuing a research career in the future. ${ }^{12}$ The investigators found that mentorship and research exposure were important for residents to achieve high levels of scholarly productivity and thus likely influential in determining their future career trajectories. Though so far uninvestigated in neurosurgery, the influence of job availability on trainees' future career trajectory is likely also important and merits attention in future research. Lawton and col- 
TABLE 2. Bivariate analysis of academic career choice among open vascular/cerebrovascular neurosurgeons $(n=83)$ versus endovascular neurosurgeons $(n=115)$

\begin{tabular}{|c|c|c|c|c|c|c|c|c|c|c|}
\hline \multirow[b]{2}{*}{ Characteristic } & \multicolumn{5}{|c|}{ Open Vascular } & \multicolumn{5}{|c|}{ Endovascular } \\
\hline & $\begin{array}{l}\text { Academic } \\
\text { Position, } \\
\text { No. }(\%)\end{array}$ & $\begin{array}{l}\text { Non-Academic } \\
\text { Position, No. } \\
(\%)\end{array}$ & $\begin{array}{c}p \\
\text { Value }\end{array}$ & OR & $\begin{array}{c}95 \% \\
\mathrm{Cl}\end{array}$ & $\begin{array}{l}\text { Academic } \\
\text { Position, } \\
\text { No. }(\%)\end{array}$ & $\begin{array}{l}\text { Non-Academic } \\
\text { Position, No. } \\
\text { (\%) }\end{array}$ & $\begin{array}{c}p \\
\text { Value }\end{array}$ & OR & $\begin{array}{c}95 \% \\
\mathrm{Cl}\end{array}$ \\
\hline \multicolumn{11}{|l|}{ Sex } \\
\hline Male & $49(64.5)$ & $27(35.5)$ & 0.10 & 4.45 & $0.67-49.72$ & $62(57.9)$ & $45(42.1)$ & 0.72 & 1.37 & $0.24-7.80$ \\
\hline Female & $2(28.6)$ & $5(71.4)$ & & & & $4(50.0)$ & $4(50.0)$ & & & \\
\hline \multicolumn{11}{|l|}{ Medical degree } \\
\hline MD & $49(62.8)$ & $29(37.2)$ & 0.37 & 2.50 & $0.27-31.64$ & $64(57.1)$ & $48(42.9)$ & $>0.99$ & 0.67 & $0.011-13.20$ \\
\hline DO & $2(40.0)$ & $3(60.0)$ & & & & $2(66.7)$ & $1(33.3)$ & & & \\
\hline \multicolumn{11}{|l|}{ Protected research time } \\
\hline$\geq 1 \mathrm{yr}$ & $47(65.3)$ & $25(34.7)$ & 0.096 & 3.24 & $0.74-16.60$ & $61(57.0)$ & $46(43.0)$ & $>0.99$ & 0.80 & $0.12-4.34$ \\
\hline$<1 \mathrm{yr}$ & $4(36.4)$ & $7(63.6)$ & & & & $5(62.5)$ & $3(37.5)$ & & & \\
\hline \multicolumn{11}{|l|}{ Pre-residency $h$-index } \\
\hline$\geq 2$ & $9(69.2)$ & $4(30.8)$ & 0.76 & 1.49 & $0.37-7.29$ & $12(63.2)$ & $7(36.8)$ & 0.62 & 1.33 & $0.44-4.36$ \\
\hline $0-1$ & $42(60.0)$ & $28(40.0)$ & & & & $54(56.3)$ & $42(43.8)$ & & & \\
\hline \multicolumn{11}{|l|}{$h$-index during residency } \\
\hline$\geq 2$ & $44(66.8)$ & $20(31.3)$ & $0.016^{*}$ & 3.71 & $1.15-12.94$ & $61(62.9)$ & $36(37.1)$ & $0.0085^{*}$ & 4.35 & $1.32-16.90$ \\
\hline $0-1$ & $7(36.8)$ & $12(63.2)$ & & & & $5(27.8)$ & $13(72.2)$ & & & \\
\hline \multicolumn{11}{|c|}{$\begin{array}{l}\text { Top } 10 \text { U.S. News research } \\
\text { medical schools (1993-2019) }\end{array}$} \\
\hline Yes & $10(83.3)$ & $2(16.7)$ & 0.12 & 3.61 & $0.69-36.26$ & $17(77.3)$ & $5(22.7)$ & 0.054 & 3.03 & $0.97-11.38$ \\
\hline No & $41(57.7)$ & $30(42.3)$ & & & & $49(52.7)$ & $44(47.3)$ & & & \\
\hline \multicolumn{11}{|c|}{$\begin{array}{l}\text { Top } 10 \text { U.S. News residency } \\
\text { programs (2007-2019) }\end{array}$} \\
\hline Yes & $16(84.2)$ & $3(15.8)$ & $0.030^{*}$ & 4.35 & $1.09-25.56$ & $16(61.5)$ & $10(38.5)$ & 0.66 & 1.25 & $0.47-3.44$ \\
\hline No & $35(54.7)$ & $29(45.3)$ & & & & $50(56.2)$ & $39(43.8)$ & & & \\
\hline \multicolumn{11}{|c|}{$\begin{array}{l}\text { Residency programs affiliated } \\
\text { w/ a top } 10 \text { U.S. News research } \\
\text { medical school (1993-2019) }\end{array}$} \\
\hline Yes & $15(83.3)$ & $3(16.7)$ & 0.053 & 3.97 & $0.99-23.43$ & $22(75.9)$ & 7 (24.1) & $0.029^{*}$ & 2.97 & $1.08-9.13$ \\
\hline No & $36(55.4)$ & $29(44.6)$ & & & & $44(51.2)$ & $42(48.8)$ & & & \\
\hline \multicolumn{11}{|c|}{$\begin{array}{l}\text { Top } 2 \text { fellowship programs (in } \\
\text { terms of no. of fellows gradu- } \\
\text { ated) }\end{array}$} \\
\hline Yes & $13(72.2)$ & $5(27.8)$ & 0.41 & 1.83 & $0.53-7.37$ & $14(70.0)$ & $6(30.0)$ & 0.32 & 1.92 & $0.63-6.63$ \\
\hline No & $38(58.5)$ & $27(41.5)$ & & & & $52(54.7)$ & $43(45.3)$ & & & \\
\hline \multicolumn{11}{|l|}{ Completing >1 fellowship } \\
\hline Yes & $26(66.7)$ & $13(33.3)$ & 0.38 & 1.51 & $0.57-4.11$ & $18(64.3)$ & $10(35.7)$ & 0.51 & 1.46 & $0.56-3.97$ \\
\hline No & $25(56.8)$ & $19(43.2)$ & & & & $48(55.2)$ & $39(44.8)$ & & & \\
\hline \multicolumn{11}{|l|}{$\mathrm{PhD}$} \\
\hline Yes & $5(71.4)$ & 2 (28.6) & 0.70 & 1.62 & $0.25-18.06$ & $4(50.0)$ & $4(50.0)$ & 0.72 & 0.73 & $0.13-4.13$ \\
\hline No & $46(60.5)$ & $30(39.5)$ & & & & $62(57.9)$ & 45 (42.1) & & & \\
\hline
\end{tabular}

$\mathrm{DO}=$ Doctor of Osteopathic Medicine; $\mathrm{MD}=$ Doctor of Medicine; $\mathrm{PhD}=$ Doctor of Philosophy.

$p$ values were obtained using Fisher's exact test.

${ }^{*}$ Statistically significant $(p<0.05)$.

leagues found that among residency graduates from the neurological surgery program at the University of California, San Francisco, favorable evaluations during the junior and chief residency years and the pursuit of a subspecialty fellowship were both significantly associated with an aca- demic career choice. ${ }^{5}$ Whereas McClelland and Daniels et al. reported that the pre-residency peer-reviewed publication number was significantly associated with academic career choice, we subsequently reported that the pre-residency publication number was not associated with 
TABLE 3. Multivariate analysis of academic career choice for open vascular neurosurgeons $(n=83)$ and endovascular neurosurgeons ( $n=115)$

\begin{tabular}{|c|c|c|c|c|c|c|}
\hline \multirow[b]{2}{*}{ Characteristic } & \multicolumn{3}{|c|}{ Open Vascular } & \multicolumn{3}{|c|}{ Endovascular } \\
\hline & $p$ Value & OR & $95 \% \mathrm{Cl}$ & $p$ Value & OR & $95 \% \mathrm{Cl}$ \\
\hline \multicolumn{7}{|l|}{$h$-index during residency } \\
\hline$\geq 2$ & $0.045^{*}$ & 3.11 & $1.04-9.84$ & $0.041^{*}$ & 3.33 & $1.10-11.51$ \\
\hline \multicolumn{7}{|l|}{$0-1$} \\
\hline \multicolumn{7}{|l|}{ Top 10 U.S. News residency programs (2007-2019) } \\
\hline Yes & 0.20 & 2.89 & $0.62-17.19$ & 0.21 & 0.35 & $0.050-1.58$ \\
\hline \multicolumn{7}{|l|}{ No } \\
\hline \multicolumn{7}{|c|}{$\begin{array}{l}\text { Residency programs affiliated w/ a top } 10 \text { U.S. News research medical school } \\
\text { (1993-2019) }\end{array}$} \\
\hline Yes & 0.55 & 1.66 & $0.32-10.26$ & $0.046^{*}$ & 5.32 & $1.22-37.96$ \\
\hline \multicolumn{7}{|l|}{ No } \\
\hline \multicolumn{7}{|l|}{ PhD } \\
\hline Yes & 0.84 & 1.21 & $0.19-10.23$ & 0.70 & 1.37 & $0.29-7.34$ \\
\hline No & & & & & & \\
\hline
\end{tabular}

* Statistically significant $(p<0.05)$.

academic career choice. ${ }^{3,6}$ In our study, we also found that pursuing an academic career was significantly associated with 2 or more publications during residency, having an $h$-index of $\geq 2$ during residency, and having devoted research time during residency. ${ }^{3}$ Choi and colleagues investigated the impact of $\mathrm{PhD}$ training on neurosurgical career choice and found that a significantly greater proportion of MD-PhD neurosurgeons held academic appointments compared with MD-only neurosurgeons. ${ }^{1}$ Crowley and colleagues demonstrated that the following in-training factors were independently predictive of residents choosing a career in academic neurosurgery: number of total publications, number of first-author publications, and attending a residency program of $\geq 2$ graduates per year. ${ }^{2}$ Finally, a study by Gelinne and colleagues showed that a slightly higher USMLE (US Medical Licensing Examination) step 1 score was associated with academic career choice, but also that the step 1 score did not predict academic rank or productivity (as measured by the $h$-index or $\mathrm{NIH}$ funding) or ABNS (American Board of Neurological Surgery) certification status. ${ }^{4}$

In other medical specialties besides neurosurgery, there has been research into academic career predictors within specific subspecialties. For example, an orthopedics study by Park and colleagues investigated factors related to choosing an academic career among a cohort of orthopedic spine surgery fellowship applicants. ${ }^{7}$ They found that completion of a research fellowship, graduation from a top 20 medical school, and a stated desire in the personal statement to become an academic surgeon were all significantly associated with an academic career in multivariate analysis.

\section{Current Study}

We sought to elucidate additional academic career predictors in neurosurgery. Similar to Park and colleagues' work, ${ }^{7}$ we sought to characterize these academic predictors within a specific subspecialty within rather than across all of neurosurgery. To account for differences in training that might arise from learning different surgical approaches to neurovascular problems, we further subdivided our cohort of vascular neurosurgeons into those who completed an open vascular fellowship and those who completed an endovascular fellowship. Comparing characteristics across open vascular and endovascular neurosurgeons, we found that the open vascular cohort completed significantly more clinical fellowships than the endovascular cohort $(\mathrm{p}=0.0014)$. Given that all other characteristics, including personal demographics, educational background, and research productivity, between the two cohorts were not significantly different, further investigation will be necessary to determine whether this finding is of importance or simply represents a limited sample size.

Notably, our multivariate analysis demonstrated that having an $h$-index of $\geq 2$ during residency was independently predictive of an academic career among both open vascular and endovascular neurosurgeon cohorts. Together, these results indicate that research productivity (as measured by the $h$-index) during residency is an important academic career predictor for both types of vascular neurosurgeons. This association could be explained by the fact that neurosurgical students and trainees with a strong interest in research and who are productive in publishing are more likely to pursue a research-focused academic neurosurgical career. Therefore, medical schools and residency programs can work toward nurturing the next generation of academic neurosurgeons by providing ample opportunities for students and trainees to engage in scholarly work and contribute to the neurosurgical literature. Additionally, our finding that fellowship program graduate output is not significantly associated with academic career choice confirms that individual research productivity during residency might be a more important factor in career choice than the specific fellowship program where one trains. 
TABLE 4. Demographics of fellowship-trained open vascular/ cerebrovascular neurosurgeons $(n=83)$ versus demographics of fellowship-trained endovascular neurosurgeons $(n=115)$

\begin{tabular}{|c|c|c|c|}
\hline \multirow[b]{2}{*}{ Characteristic } & \multicolumn{2}{|c|}{ No. of Neurosurgeons (\%) } & \multirow[b]{2}{*}{$\begin{array}{c}\mathrm{p} \\
\text { Value }\end{array}$} \\
\hline & $\begin{array}{c}\text { Open } \\
\text { Vascular }\end{array}$ & Endovascular & \\
\hline \multicolumn{4}{|l|}{ Sex } \\
\hline Male & $76(91.6)$ & $107(93.0)$ & 0.79 \\
\hline Female & $7(8.4)$ & $8(7.0)$ & \\
\hline \multicolumn{4}{|l|}{ Academic position } \\
\hline Yes & $51(61.4)$ & $66(57.4)$ & 0.66 \\
\hline No & $32(38.6)$ & $49(42.6)$ & \\
\hline \multicolumn{4}{|l|}{ Residency graduation yr } \\
\hline$\leq 2004$ & $5(6.0)$ & $1(.6)$ & - \\
\hline $2005-2009$ & $32(38.6)$ & $36(23.2)$ & \\
\hline $2010-2014$ & $31(37.3)$ & $56(48.7)$ & \\
\hline$\geq 2015$ & $15(18.1)$ & $22(14.2)$ & \\
\hline \multicolumn{4}{|c|}{$\begin{array}{l}\text { Residency program length, } \\
\text { yrs }\end{array}$} \\
\hline 6 & $18(21.7)$ & $30(26.1)$ & 0.51 \\
\hline 7 & $65(78.3)$ & $85(73.9)$ & \\
\hline \multicolumn{4}{|c|}{$\begin{array}{l}\text { Top } 10 \text { U.S. News research } \\
\text { medical schools (1993-2019) }\end{array}$} \\
\hline Yes & $12(14.5)$ & $22(19.1)$ & 0.45 \\
\hline No & $71(85.5)$ & $93(80.9)$ & \\
\hline \multicolumn{4}{|c|}{$\begin{array}{l}\text { Top } 10 \text { U.S. News residency } \\
\text { programs (2007-2019) }\end{array}$} \\
\hline Yes & $19(22.9)$ & $26(22.6)$ & $>0.99$ \\
\hline No & 64 (77.1) & $89(77.4)$ & \\
\hline \multicolumn{4}{|c|}{$\begin{array}{l}\text { Residency programs affili- } \\
\text { ated w/ a top } 10 \text { U.S. News } \\
\text { research medical school } \\
\text { (1993-2019) }\end{array}$} \\
\hline Yes & $18(21.7)$ & $29(25.2)$ & 0.61 \\
\hline No & $65(78.3)$ & $86(74.8)$ & \\
\hline \multicolumn{4}{|l|}{ Protected research time } \\
\hline$\geq 1 \mathrm{yr}$ & $72(86.7)$ & $107(93.0)$ & 0.15 \\
\hline$<1 \mathrm{yr}$ & $11(13.3)$ & $8(7.0)$ & \\
\hline \multicolumn{4}{|l|}{ Pre-residency $h$-index } \\
\hline$\geq 2$ & $13(15.7)$ & $19(16.5)$ & 0.46 \\
\hline $0-1$ & $70(84.3)$ & $96(83.5)$ & \\
\hline \multicolumn{4}{|c|}{$h$-index during residency } \\
\hline$\geq 2$ & 64 (77.1) & $97(84.3)$ & 0.24 \\
\hline $0-1$ & $19(22.9)$ & $18(15.7)$ & \\
\hline \multicolumn{4}{|l|}{ Post-residency $h$-index } \\
\hline$\geq 2$ & $52(62.7)$ & $69(60.0)$ & 0.38 \\
\hline $0-1$ & $31(37.3)$ & $46(40.0)$ & \\
\hline
\end{tabular}

\section{» CONTINUED FROM PREVIOUS COLUMN}

TABLE 4. Demographics of fellowship-trained open vascular/ cerebrovascular neurosurgeons $(n=83$ ) versus demographics of fellowship-trained endovascular neurosurgeons $(n=115)$

\begin{tabular}{|c|c|c|c|}
\hline & No. of $\mathrm{Nel}$ & osurgeons (\%) & \\
\hline Characteristic & $\begin{array}{c}\text { Open } \\
\text { Vascular }\end{array}$ & Endovascular & $\begin{array}{c}p \\
\text { Value }\end{array}$ \\
\hline
\end{tabular}

No. of clinical fellowships completed

\begin{tabular}{lccc}
\hline 1 & $50(60.2)$ & $93(80.9)$ & $0.0014^{*}$ \\
\hline 2 & $26(31.3)$ & $18(15.7)$ & \\
\hline 3 & $6(7.2)$ & $3(2.6)$ & \\
\hline 4 & $1(1.2)$ & $1(.9)$ & \\
\hline Medical degree & & & \\
\hline MD & $78(94.0)$ & $112(97.4)$ & 0.28 \\
\hline Other higher degree & $5(6.0)$ & $3(2.6)$ & \\
\hline MS & & & \\
\hline MSt & $3(3.6)$ & $5(4.3)$ & - \\
\hline MPH & $1(1.2)$ & $0(0.0)$ & \\
\hline MBA & $2(2.4)$ & $4(3.5)$ & \\
\hline PhD & $2(2.4)$ & $2(1.7)$ & \\
\hline
\end{tabular}

MBA = Master of Business Administration; MPH = Master of Public Health; MS $=$ Master of Science; $\mathrm{MSt}=$ Master of Studies.

Categorical variables were compared using Fisher's exact test and continuous variables were analyzed using the Mann-Whitney U-test.

* Statistically significant $(p<0.05)$.

Interestingly, while attendance of a residency program affiliated with a top research medical school was independently associated with academic career choice among endovascular neurosurgeons, the same association was not seen among the open vascular cohort. One possible explanation for this finding may be that the formation of professional networks at research-focused teaching hospitals leading trainees to pursue academic careers following their neurosurgical training may be more important among endovascular neurosurgeons. Many other types of reasons are plausible, and further investigation is needed to delineate the reasons for this observed difference between our two cohorts. Our results indicate that, even within a single neurosurgical subspecialty, career choice is multifactorial and can vary between different groups of trainees. We hope that our study serves to spur further research into the influence of personal characteristics and training environments on career choice in other neurosurgical subspecialties in order to provide better and more personalized mentoring to students and trainees.

\section{Limitations}

There are several limitations to our study. First, data gathered from public online sources may not be entirely accurate or up to date. Second, we defined an academic career as being employed at a hospital with an affiliated neurosurgical residency program; studies using a different definition of an academic career, such as one based on 
TABLE 5. Demographics of neurosurgeons who completed both an open vascular and an endovascular fellowship $(n=19)$

No. of

Neurosurgeons

Characteristic

$(\%)$

\begin{tabular}{|c|c|}
\hline \multicolumn{2}{|l|}{ Sex } \\
\hline Male & $17(89.5)$ \\
\hline Female & $2(10.5)$ \\
\hline \multicolumn{2}{|c|}{ Academic position } \\
\hline Yes & $13(68.4)$ \\
\hline No & $6(31.6)$ \\
\hline \multicolumn{2}{|c|}{ Residency graduation year } \\
\hline$\leq 2004$ & $0(0.0)$ \\
\hline 2005-2009 & $9(47.4)$ \\
\hline $2010-2014$ & $5(26.3)$ \\
\hline$\geq 2015$ & $5(26.3)$ \\
\hline \multicolumn{2}{|c|}{ Residency program length, yrs } \\
\hline 6 & $4(21.1)$ \\
\hline 7 & $15(78.9)$ \\
\hline \multicolumn{2}{|c|}{$\begin{array}{l}\text { Top } 10 \text { U.S. News research medical schools } \\
\text { (1993-2019) }\end{array}$} \\
\hline Yes & $2(10.5)$ \\
\hline No & $17(89.5)$ \\
\hline \multicolumn{2}{|c|}{ Top 10 U.S. News residency programs (2007-2019) } \\
\hline Yes & $2(10.5)$ \\
\hline No & $17(89.5)$ \\
\hline \multicolumn{2}{|c|}{$\begin{array}{l}\text { Residency programs affiliated w/ a top } 10 \text { U.S. } \\
\text { News research medical school (1993-2019) }\end{array}$} \\
\hline Yes & $1(5.3)$ \\
\hline No & $18(94.7)$ \\
\hline \multicolumn{2}{|c|}{ Protected research time } \\
\hline$\geq 1 \mathrm{yr}$ & $17(89.5)$ \\
\hline$<1 \mathrm{yr}$ & $2(10.5)$ \\
\hline \multicolumn{2}{|c|}{ Pre-residency $h$-index } \\
\hline$\geq 2$ & $2(10.5)$ \\
\hline $0-1$ & $17(89.5)$ \\
\hline \multicolumn{2}{|c|}{$h$-index during residency } \\
\hline$\geq 2$ & $18(94.7)$ \\
\hline $0-1$ & $1(5.3)$ \\
\hline \multicolumn{2}{|c|}{ Post-residency $h$-index } \\
\hline$\geq 2$ & $14(73.7)$ \\
\hline $0-1$ & $5(26.3)$ \\
\hline \multicolumn{2}{|c|}{ No. of clinical fellowships completed } \\
\hline 1 & $0(0.0)$ \\
\hline 2 & $15(78.9)$ \\
\hline 3 & $3(15.8)$ \\
\hline 4 & $1(5.3)$ \\
\hline \multicolumn{2}{|l|}{ Medical degree } \\
\hline $\mathrm{MD}$ & $18(94.7)$ \\
\hline DO & $1(5.3)$ \\
\hline
\end{tabular}

» CONTINUED FROM PREVIOUS COLUMN

TABLE 5. Demographics of neurosurgeons who completed both an open vascular and an endovascular fellowship $(n=19)$

No. of

Neurosurgeons

Characteristic

\begin{tabular}{cc}
\hline Other higher degree & \\
\hline MS & $1(5.3)$ \\
\hline MSt & $0(0.0)$ \\
\hline MPH & $1(5.3)$ \\
\hline MBA & $0(0.0)$ \\
\hline PhD & $1(5.3)$ \\
\hline
\end{tabular}

research productivity or NIH funding, may lead to results that are different from ours. Third, our study was a retrospective review using data from specific online sources and therefore might suffer from selection bias. Fourth, our ranking of vascular fellowship programs by the number of fellows in our cohort that they graduated is an imperfect proxy for estimating how many fellows these programs truly produced over the time period we studied. Fifth, U.S. News and World Report rankings are contentious proxies for gauging academic standing. However, our use of these rankings was for the purpose of determining if an association existed with career trajectory rather than validating these specific ranking methodologies. By compiling and utilizing rankings over a number of decades, we hoped to partially account for the variability of what has been considered a "top" program over the time period that our residency alumni/alumnae cohort was studied. The use of U.S. News and World Report rankings in investigating academic career choice is also well documented in the literature ${ }^{13,14}$ Finally, our cohorts consisted of 83 open vascular neurosurgeons and 115 endovascular neurosurgeons; it would be ideal to validate our study with a larger sample of alumni/alumnae in the future. Acknowledging these limitations, we are nevertheless confident that our experimental design and statistical analyses yielded informative and novel results regarding career predictors within vascular neurosurgery that will be helpful in mentoring students and trainees based on their future career goals.

\section{Conclusions}

Within a cohort of fellowship-trained vascular neurosurgeons, an $h$-index of $\geq 2$ during residency was an independent predictor of academic career choice among both open vascular and endovascular neurosurgeons. Additionally, attendance of a residency program affiliated with a top research medical school independently predicted academic career choice among endovascular neurosurgeons. Our study highlights the complex, multifactorial nature of academic career choice even within a single neurosurgical subspecialty. Our results could be useful in improving mentoring for students and trainees interested in vascular neurosurgery and could also be helpful in identifying those with high potential for careers in academic medicine. 
TABLE 6. Open vascular and cerebrovascular fellowship programs $(n=83)$ versus endovascular fellowship programs $(n=115)$

\begin{tabular}{|c|c|c|c|}
\hline Open Vascular Program Name* & $\begin{array}{l}\text { No. of Fellows } \\
\text { Graduated }\end{array}$ & Endovascular Program Name† & $\begin{array}{c}\text { No. of Fellows } \\
\text { Graduated }\end{array}$ \\
\hline Barrow Neurological Institute & 11 & University at Buffalo & 11 \\
\hline Thomas Jefferson University & 6 & Barrow Neurological Institute & 10 \\
\hline Emory University & 5 & University of Florida & 9 \\
\hline University of Miami & 4 & Thomas Jefferson University & 8 \\
\hline University of South Florida & 4 & Albany Medical College & 5 \\
\hline University of Washington & 4 & Harvard University & 5 \\
\hline Capital Health System & 3 & Semmes Murphey Clinic & 2 \\
\hline Harvard University & 3 & University of Pittsburgh & 5 \\
\hline Oregon Health \& Science University & 3 & Cornell University & 4 \\
\hline University at Buffalo & 3 & University of Miami & 4 \\
\hline University of California, San Francisco & 3 & Capital Health System & 3 \\
\hline University of Illinois & 3 & Emory University & 3 \\
\hline Drexel University & 2 & Johns Hopkins University & 3 \\
\hline Indiana University & 2 & University of Alabama & 3 \\
\hline Johns Hopkins University & 2 & Wayne State University & 3 \\
\hline Semmes Murphey Clinic & 2 & Baptist Health System & 2 \\
\hline Swedish Neuroscience Institute & 2 & Cedars-Sinai Medical Center & 2 \\
\hline University of California, Irvine & 2 & Drexel University & 2 \\
\hline Arkansas Neuroscience Institute & 1 & Duke University & 2 \\
\hline Arrowhead Regional Medical Center & 1 & Icahn School of Medicine at Mount Sinai & 2 \\
\hline Cornell University & 1 & Rush University & 2 \\
\hline Baptist Medical Center & 1 & University of Cincinnati & 2 \\
\hline George Washington University & 1 & University of Wisconsin & 2 \\
\hline Helsinki University Central Hospital, Finland & 1 & Vanderbilt University & 2 \\
\hline Icahn School of Medicine at Mount Sinai & 1 & Washington University in St. Louis & 2 \\
\hline Indianapolis Neurosurgical Group & 1 & Auckland City Hospital, New Zealand & 1 \\
\hline Louisiana State University & 1 & Case Western Reserve University-University Hospitals & 1 \\
\hline Macquarie University, Australia & 1 & Christchurch Hospital, New Zealand & 1 \\
\hline Northwestern University & 1 & Cleveland Clinic & 1 \\
\hline Saint Louis University & 1 & Ohio State University & 1 \\
\hline Stanford University & 1 & Saint John Providence Health System & 1 \\
\hline University of Arkansas & 1 & Stanford University & 1 \\
\hline University of Cincinnati & 1 & State University of New York, Upstate Medical University & 1 \\
\hline University of Colorado & 1 & Swedish Neuroscience Institute & 1 \\
\hline University of Louisville & 1 & Tufts University & 1 \\
\hline University of Tennessee & 1 & University of California, Los Angeles & 1 \\
\hline University of Toronto, Canada & 1 & University of Illinois & 1 \\
\hline University of Utah & 1 & University of Louisville & 1 \\
\hline Vanderbilt University & 1 & University of Michigan & 1 \\
\hline \multirow[t]{8}{*}{ Washington University in St. Louis } & 1 & University of Minnesota & 1 \\
\hline & & University of Southern California & 1 \\
\hline & & University of Tennessee & 1 \\
\hline & & University of Texas at Houston & 1 \\
\hline & & University of Virginia & 1 \\
\hline & & Virginia Commonwealth University & 1 \\
\hline & & Wake Forest University & 1 \\
\hline & & World Federation of Neurosurgical Societies, Japan & 1 \\
\hline
\end{tabular}

* Thirty-three graduates completed more than 1 fellowship.

$\dagger$ Twenty-two graduates completed more than 1 fellowship. 


\section{References}

1. Choi BD, DeLong MR, DeLong DM, et al. Impact of PhD training on scholarship in a neurosurgical career. J Neurosurg. 2014;120(3):730-735.

2. Crowley RW, Asthagiri AR, Starke RM, et al. In-training factors predictive of choosing and sustaining a productive academic career path in neurological surgery. Neurosurgery. 2012;70(4):1024-1032.

3. Daniels M, Garzon-Muvdi T, Maxwell R, et al. Preresidency publication number does not predict academic career placement in neurosurgery. World Neurosurg. 2017;101:350-356.

4. Gelinne A, Zuckerman S, Benzil D, et al. United States Medical Licensing Exam Step I score as a predictor of neurosurgical career beyond residency. Neurosurgery. 2019;84(5):1028-1034.

5. Lawton MT, Narvid J, Quiñones-Hinojosa A. Predictors of neurosurgical career choice among residents and residency applicants. Neurosurgery. 2007;60(5):934-939.

6. McClelland S III. Pre-residency peer-reviewed publications are associated with neurosurgery resident choice of academic compared to private practice careers. J Clin Neurosci. 2010;17(3):287-289.

7. Park DK, Rhee JM, Wu B, Easley K. Factors related to choosing an academic career track among spine fellowship applicants. Spine (Phila Pa 1976). 2013;38(5):425-433.

8. Ajmera S, Lee RP, Schultz A, et al. Postgraduate publishing output in pediatric neurosurgery: correlation with fellowship site and individual scholars. J Neurosurg Pediatr. 2019;24(3):343-351.

9. Kalra RR, Kestle JRW. An assessment of academic productivity in pediatric neurosurgery. $J$ Neurosurg Pediatr. 2013;12(3):262-265.

10. Sarkiss CA, Riley KJ, Hernandez CM, et al. Academic productivity of US neurosurgery residents as measured by h-in- dex: program ranking with correlation to faculty productivity. Neurosurgery. 2017;80(6):975-984.

11. Brem H, Amundson E. Preparing Hopkins medical students for a career in academic neurosurgery. Surgery. 2003;134(3):414-415.

12. Karsy M, Henderson F, Tenny S, et al. Attitudes and opinions of US neurosurgical residents toward research and scholarship: a national survey. J Neurosurg. 2018;131(1):252-263.

13. Dorsey ER, Raphael BA, Balcer LJ, Galetta SL. Predictors of future publication record and academic rank in a cohort of neurology residents. Neurology. 2006;67(8):1335-1337.

14. Grimm LJ, Shapiro LM, Singhapricha T, et al. Predictors of an academic career on radiology residency applications. Acad Radiol. 2014;21(5):685-690.

\section{Disclosures}

Judy Huang is a stockholder of Longeviti Neuro Solutions.

\section{Author Contributions}

Conception and design: Khalafallah, Jimenez. Acquisition of data: Jimenez. Analysis and interpretation of data: Khalafallah, Jimenez. Drafting the article: Khalafallah, Jimenez. Critically revising the article: all authors. Reviewed submitted version of manuscript: all authors. Approved the final version of the manuscript on behalf of all authors: Tamargo. Statistical analysis: Jimenez. Study supervision: Tamargo.

\section{Correspondence}

Rafael J. Tamargo: Johns Hopkins University School of Medicine, Baltimore, MD.rtamarg@jhmi.edu. 